\title{
Obtaining Cellulose Fibers from the Fallen Leaves of the Elm
}

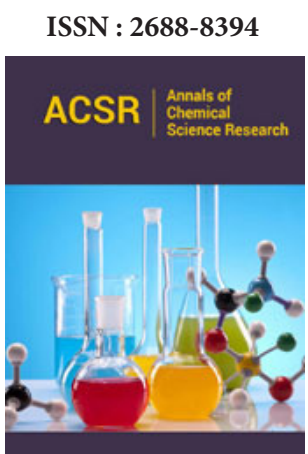

*Corresponding author: Mansurov ZA, Al Farabi Kazakh National University, Institute of combustion problems, Kazakhstan

Submission: 眥 August 20, 2021

Published: 傮 October 05, 2021

Volume 2 - Issue 5

How to cite this article: Taurbekov AT, Mansurov ZA* and Chernoglazova TV, Obtaining Cellulose Fibers from the Fallen Leaves of the Elm. Ann Chem Sci Res. 2(5). ACSR. 000546. 2021. DOI: 10.31031/ACSR.2021.02.000546

Copyright@ Mansurov ZA, This article is distributed under the terms of the Creative Commons Attribution 4.0 International License, which permits unrestricted use and redistribution provided that the original author and source are credited.

\author{
Taurbekov AT ${ }^{1,2}$, Mansurov ZA',2* and Chernoglazova TV² \\ ${ }^{1}$ Al Farabi Kazakh National University, Kazakhstan \\ ${ }^{2}$ Institute of combustion problems, Kazakhstan
}

\begin{abstract}
This investigation presents a method for obtaining cellulose fibers from fallen leaves using chemicalthermal treatment. The aim of this work is to investigate the possibility of using fallen leaves as an alternative source of cellulose. The relevance of research lies in the disposal of waste raw materials in the form of fallen leaves, which are an annual multi-tonnage raw material.
\end{abstract}

Keywords: Cellulose; Lignin; Chemical heat treatment; Fibers

\section{Introduction}

Cellulose and its derivatives are the most common polymers in nature [1]. The wide range of products made from cellulose determines the need for constant growth of its production. Cellulose is composed of beta-1,4-linked glucopyranose groups, which form a linear homopolymer (Figure 1). It is an important structural component of the cell walls of various organisms of plant materials [2]. To extract cellulose from plant biomass, it is necessary to free it from other plant tissue substances-hemicellulose, resins and fats by means of chemical heat treatment [3]. The main component to get rid of, when producing cellulose, is lignin. The process of removing lignin from chopped wood is called delignification [4]. Depending on how completely lignin and hemicellulose are dissolved in the process of chemical-thermal treatment, the properties of cellulose fibers change. Thus, the quality indicators of cellulose depend both on the choice of raw materials and on the methods and conditions of its processing, which make it possible to provide a different degree of removal of lignin and other substances accompanying cellulose. The cell walls of plants are built mainly from cellulose, so plant raw materials are the only source of industrial cellulose production.

Currently, the main source of cellulose is wood, the processing of which is an energyintensive and environmentally unsafe process, during which a large amount of industrial waste is generated [5]. In addition, in recent years, there has been a shortage of wood resources all over the world, therefore, in order to conserve forests and preserve the environment, it is necessary to partially or completely replace them with renewable plant biomass. In recent years, interest in large-tonnage renewable waste from agriculture and municipal economy has sharply increased. The main alternative and promising source of raw materials for the production of technical cellulose and cellulose fibers is non-woody annual plants, in which the cell walls are built of cellulose. Table 1 shows the comparative indicators of the components of non-woody annuals such as: rye straw, grass, rice husks, reeds and cotton [6].

Another valuable source of cellulosic raw material is fallen leaves of trees, which has a number of advantages - wide distribution, low cost and an annually renewable natural resource [7]. Disposal of fallen leaves is currently an environmental problem, because emissions from burning leaves lead to air pollution with toxic compounds, or when removing or burning municipal solid waste [8]. Processing and rational use of this type of renewable plant material is an urgent problem. According to statistics, as of January 2019, more than 2.2 million green plantations were counted in Almaty, which annually produce about 55,000 tons of foliage. This waste has a "zero" cost and can be used to produce cellulosic fibers. 
Table 1: Comparative indicators of cellulose from nonwood raw materials.

\begin{tabular}{|c|c|c|c|c|c|}
\hline Index & Rye Straw & Grass & Rice Husk & Cane & Cotton \\
\hline \multicolumn{7}{|c|}{ Content, mass. \%: } \\
\hline cellulose & 56.9 & 60.1 & 50.3 & 59.4 & 65.8 \\
\hline lignin & 7.95 & 5.69 & 4.81 & 6.74 & - \\
\hline pentosans & 23.1 & 24.9 & 18.1 & 19.9 & 18.2 \\
\hline ash & 7.21 & 5.05 & 10.5 & 6.68 & 3.79 \\
\hline
\end{tabular}

\section{Experimental Part}

In the work, we used elm leaves fallen off in the autumn period of 2020 on the territory of the park named after I. Baytyrsunov in the city of Almaty. For the production of cellulose, chemical-thermal treatment was used: washing, grinding, homogenization, alkaline cooking, extraction, washing, ultrasonic treatment, drying.

\section{Determination of the component composition of plant raw materials}

Table 2: Chemical composition of leaves

\begin{tabular}{|c|c|c|}
\hline \multirow{2}{*}{ Components } & \multicolumn{2}{|c|}{ Content, \% } \\
\cline { 2 - 3 } & $\begin{array}{c}\text { Before chemical-thermal } \\
\text { treatment }\end{array}$ & $\begin{array}{c}\text { After chemical-thermal } \\
\text { treatment }\end{array}$ \\
\hline Cellulose & 55.1 & 84.5 \\
\hline Lignin & 37.2 & 14.8 \\
\hline Ash & 7.1 & 6.3 \\
\hline
\end{tabular}

Determination of the content of alpha-cellulose in the product before and after chemical-thermal treatment of fallen leaves of elm was carried out in accordance with GOST 6840-78 (data are presented in Table 2). This International Standard applies to cellulose and specifies a method for the quantitative determination of alpha cellulose content. The essence of the method consists in processing cellulose with $17.5 \%$ sodium hydroxide solution and quantitative determination of the dissolved residue after washing with $9.5 \%$ sodium hydroxide solution with water and drying. Determination of the lignin content in the product before and after the chemical-thermal treatment of fallen elm leaves was carried out in accordance with GOST 11960-79 (the data are presented in Table 2). The method is based on hydrolysis of fibrous materials and raw materials with a mixture of sulfuric and phosphoric acids, previously subjected to extraction with methylene chloride. The determination of the ash content in the product before and after the chemical-thermal treatment of fallen elm leaves was carried out in accordance with GOST 18461-93 (the data are presented in Table 2).

\section{Mechanical processing of material}

For preliminary cleaning of the feedstock from small mechanical impurities in the form of dirt, dust and other solid waste, the foliage was crushed to a dimension of $1-2 \mathrm{~mm}$ and passed through a vibrating screen. The obtained material in the amount of $50 \mathrm{~g}$ was dispersed in distilled water with a volume of 2 liters and homogenized by mechanical crushing on a Silverson L5A "shaker" at 6000rpm for 15 minutes. Mechanical processing of the raw material allows the surface of the material to be prepared for the formation of inter-fiber bonds and enhance the ability of cellulose fibers to bind with each other. This effect is achieved due to the partial destruction and removal of the outer cell membranes, giving the fibers flexibility and plasticity due to the weakening and destruction of interfibrillar bonds of the secondary cell wall (fiber fibrillation). It is also worth noting the effect of mechanical treatment on the loosening of cellulose fibers and hemicellulose in interfibrillar spaces and on the surface of fibrils (that is, fiber hydration during grinding).

\section{Chemical heat treatment of crushed material}

After preparing the raw material, $10 \mathrm{~g}$ of the pre-homogenized material was mixed with 10,20 and $30 \%$ concentrated $\mathrm{NaOH}$ solution in a volume of $100 \mathrm{ml}$. The ratio of solid to liquid is $1: 10$. The sample was thoroughly mixed at different temperatures of 50 , 70 and $90^{\circ} \mathrm{C}$ for different time intervals $(60,90$ and 120 minutes) to determine the optimal temperature and duration of delignification. An IKA RW 16 basic magnetic stirrer was used for stirring. In the process of chemical-thermal treatment, the cellulose of the leaves was split into thin fibers. The final stage was the purification of the isolated cellulose. The resulting pulp was washed in distilled water to neutral $\mathrm{pH}$ using an ultrasonic bath. Sonication also allowed for the cleavage of cellulose into finer fibers. The regularities of the thermal destruction of foliage were assessed using a microscope.

\section{Examination by optical and scanning electron microscopy}

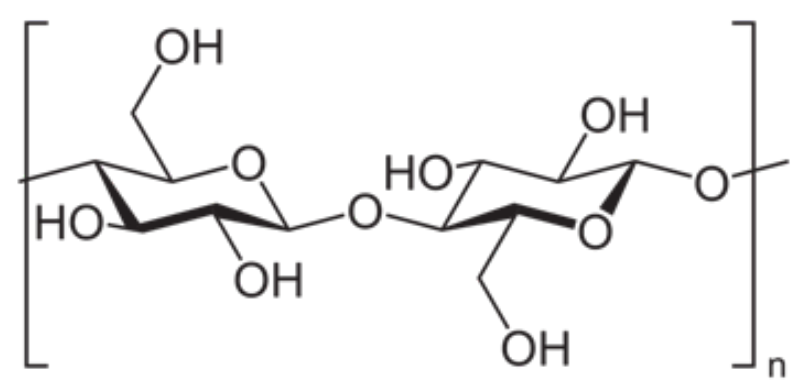

Figure 1: Structure of cellulose [1].

The samples obtained were preliminarily dehydrated in a drying oven at a temperature of $80^{\circ} \mathrm{C}$ for 2 hours. After drying, the material was fixed on the surface of a glass slide to investigate the microstructure on an optical microscope Digital Q1 Microscopes (China) at a magnification of 200 times. A detailed analysis of the external morphological structure of the obtained samples was carried out using scanning electron microscopy (SEM) (Quantum 3D 200i Dual System, USA) and a JEO JSM-6490LA scanning electron microscope. To determine the elemental composition of the obtained fibers, the method of energy dispersive X-ray spectroscopy (EDX) was used. Images of optical and SEM microscopy of the obtained cellulose fibers are shown in Figure $2 \& 4$, respectively.

\section{Results and Discussion}

Table 2 shows the results of a study of the component composition of the original plant material (elm leaves). The 
predominant component of foliage is cellulose (fiber)-55.1\%. The amorphous polymer content of lignin is $37.2 \%$. This lignin/cellulose ratio is typical for annual plants. After chemothermal treatment, the cellulose content is $84.5 \%$, and the amorphous lignin content decreased to $14.8 \%$. As a result, during alkaline chemical-thermal

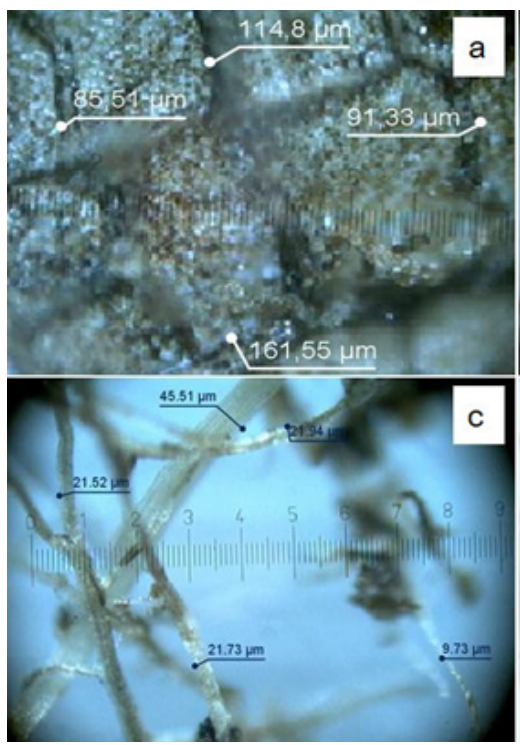

treatment, the destruction of intermolecular ether bonds, which are stitched with hemicelluloses and lignin, occurs. Also, the effect of alkali on cellulose microfibrils reduces the degree of cellulose polymerization and cellulose swells, this leading to an increase in its fibers.

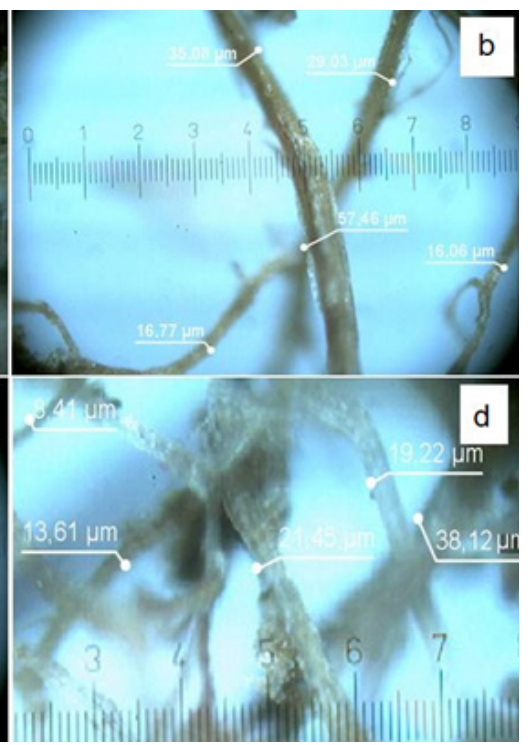

Figure 2: The structure of cellulose fibers after chemical thermal treatment: (a) leaves; (b) $2 \mathrm{M} \_90{ }^{\circ} \mathrm{C} \_2 \mathrm{~h}$; (c) $5 \mathrm{M} \_90{ }^{\circ} \mathrm{C} \_2 \mathrm{~h} ;(\mathrm{d}) ; 7 \mathrm{M} \_90{ }^{\circ} \mathrm{C} \_2 \mathrm{~h}$.
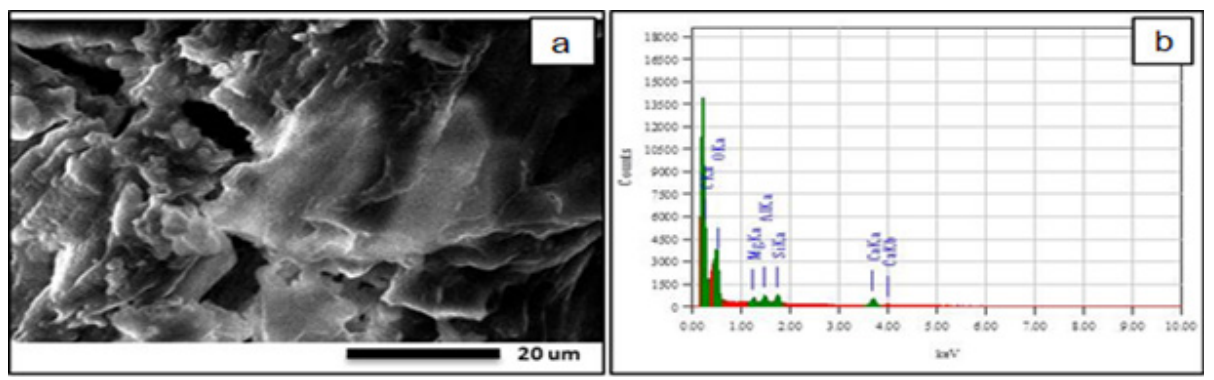

Figure 3: SEM (a) and EDX (b) elemental analysis of the sample after alkaline cooking.

Table 3: Changes in the diameter of cellulose fibers with different processing.

\begin{tabular}{|c|c|c|}
\hline № & Chemical Heat Treatment & Average Fiber Diameter, $(\boldsymbol{\mu m})$ \\
\hline 1 & Original fallen leaf & 113.31 \\
\hline 2 & $2 \mathrm{M}_{-} 90^{\circ} \mathrm{C} \_2 \mathrm{~h}$ & 30.88 \\
\hline 3 & $5 \mathrm{M}_{-} 90^{\circ} \mathrm{C} \_2 \mathrm{~h}$ & 24.08 \\
\hline 4 & $7 \mathrm{M}_{-} 90^{\circ} \mathrm{C} \_2 \mathrm{~h}$ & 20.16 \\
\hline
\end{tabular}

Table 3 shows the results of the average diameter of the obtained fibers before and after chemical-thermal treatment of the starting material under different conditions. As a result of alkaline treatment, active dissolution of organic substances of the raw material present in the composition of the starting material is observed, which begins already at low temperatures when the raw material comes into contact with an alkaline solution. During the reaction, the solution is actively colored brown, which is characteristic of lignin dissolution.
Figure 2 shows images of an optical microscope of the structure of cellulose fibers of the original product and after various chemical-thermal treatment. A significant decrease in the size of cellulose fibers after chemical-thermal treatment is clearly visible. The results of thermochemical treatment show a significant change in the structure and diameter of cellulose fibers towards their decrease with an increase in alkali concentration from $2 \mathrm{M}$ to $7 \mathrm{M}$ and processing time, the data are presented in Table 3.

Figure 3 shows SEM images of cellulose fiber samples, where a rough surface with many cellulose layers is observed, which may indicate an intense alkaline treatment effect. In addition to delignification, the destruction of polysaccharides (hemicellulose, pectin, lignin and others) present in the composition of the feedstock occurs. As a result of the destruction of polysaccharides, a weight loss of the final product is observed. The decrease in mass can reach from 10 to $70 \%$ of the original weight, depending on the conditions of chemical-thermal treatment. 
Figure 4 shows the results of chemical-thermal treatment of the initial product depending on the temperature and time of treatment at alkali concentrations of $2 \mathrm{M}(\mathrm{NaOH})$. It is found that when processing the raw material at $50{ }^{\circ} \mathrm{C}, 2 \mathrm{M}(\mathrm{a})$, the product yield has average values in the range of $45-52 \%$, the maximum product yield was achieved when processing the material for no more than 90 minutes. When processing raw materials at $70{ }^{\circ} \mathrm{C}, 2 \mathrm{M}, 90$ minutes (b), the highest product yield was achieved in comparison with other processing conditions. An increase in temperature to $90{ }^{\circ} \mathrm{C}(\mathrm{c})$ negatively affected the yield of the product, regardless of the processing time. The minimum value of the product yield was $44.7 \%$ at $90{ }^{\circ} \mathrm{C}, 2 \mathrm{M}, 90$ minutes.

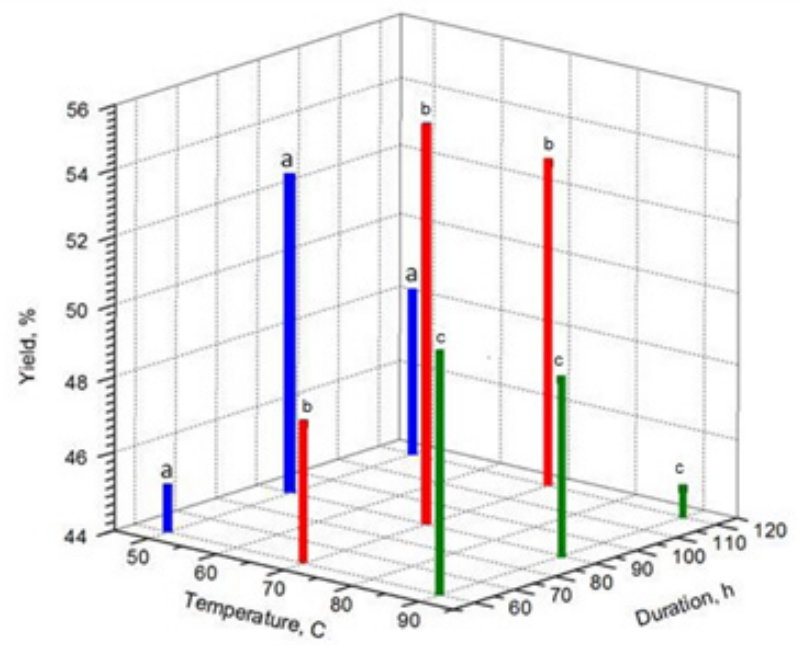

Figure 4: Product yield as a function of temperature and processing time at alkali concentrations of $2 \mathrm{M}(\mathrm{NaOH})$ : (a) $50{ }^{\circ} \mathrm{C}$, (b) $70^{\circ} \mathrm{C}$, (c) $90^{\circ} \mathrm{C}$.

Table 4: Product yield depending on alkali concentrations, temperature and processing time.

\begin{tabular}{|c|c|c|c|}
\hline Alkali Concentration $(\mathrm{NaOH}), \mathrm{mol}$ & Temperature $\left({ }^{\circ} \mathrm{C}\right)$ & Cooking Duration (min) & Exit, \% \\
\hline \multirow{9}{*}{$2 \mathrm{M}$} & \multirow{3}{*}{50} & 60 & 45.1 \\
\hline & & 90 & 52.6 \\
\hline & & 120 & 48.2 \\
\hline & \multirow{3}{*}{70} & 60 & 47.6 \\
\hline & & 90 & 55.1 \\
\hline & & 120 & 52.8 \\
\hline & \multirow{3}{*}{90} & 60 & 50.4 \\
\hline & & 90 & 48.6 \\
\hline & & 120 & 44.7 \\
\hline \multirow{9}{*}{$5 \mathrm{M}$} & \multirow{3}{*}{50} & 60 & 52.8 \\
\hline & & 90 & 57.4 \\
\hline & & 120 & 54.9 \\
\hline & \multirow{3}{*}{70} & 60 & 55.9 \\
\hline & & 90 & 58.4 \\
\hline & & 120 & 53.7 \\
\hline & \multirow{3}{*}{90} & 60 & 58.4 \\
\hline & & 90 & 66.8 \\
\hline & & 120 & 59.7 \\
\hline \multirow{6}{*}{$7 \mathrm{M}$} & \multirow{3}{*}{50} & 60 & 48.3 \\
\hline & & 90 & 54.4 \\
\hline & & 120 & 49.9 \\
\hline & \multirow{3}{*}{70} & 60 & 47.9 \\
\hline & & 90 & 58.2 \\
\hline & & 120 & 56.4 \\
\hline
\end{tabular}




\begin{tabular}{|l|l|l|l|}
\hline \multirow{2}{*}{90} & 60 & 51.4 \\
\cline { 2 - 3 } & & 90 & 58.6 \\
\hline
\end{tabular}

Table 4 presents detailed data on the effect of the modes of chemical thermal treatment at various concentrations, temperatures and time on the final product yield. With an increase in temperature from 50 to $90{ }^{\circ} \mathrm{C}$ and a processing time from 60 to 120 minutes, the product yield changed from 45 to $67 \%$. The chemical thermal treatment of the starting material shows that an increase in the holding time of the cellulose-containing raw material led to a decrease in the yield of cellulose. This can be explained by the fact that during the cooking of foliage, cellulose is protected from the action of alkali by lignin, therefore the destructive effect of the medium manifested itself by the end of cooking: a decrease in the degree of polymerization, partial dissolution of cellulose and, consequently, a decrease in the yield of the latter.

\section{Conclusion}

As a result of the research, a method was developed for obtaining cellulose fibers from fallen leaves of elm with high quality indicators. The main factors of delignification for obtaining cellulose fibers were determined (duration 90 minutes, processing temperature $90{ }^{\circ} \mathrm{C}$ at a concentration of $5 \mathrm{M} \mathrm{NaOH}$ ), the maximum yield of the final product was $66.8 \%$.

\section{References}

1. Barbash VA, Trembus IV, Shevchenko VM (2009) Organosolv methods for obtaining fibrous semifinished products from wheat straw. Energy technologies and resource conservation 1: 37-41.
2. Barmin MI, Hrebenkin AN, Boiko AI (2004) Obtaining microcrystalline cellulose from waste products of flax production/News of higher educational establishments. Chemistry and chemical technology 47(3): 156158.

3. Klemm D, Heublein B, Fink HP, Bohn A (2005) Cellulose: fascinating biopolymer and sustainable raw material. Angew Chem Int Ed 44-49: 3358-3393.

4. Nechyporchuk O, Belgacem MN, Bras J (2016) Production of cellulose nanofibrils: a review of recent advances. Ind Crops Prod 93: 2-25.

5. Serge Rebouillat, Fernand Pla (2013) State of the art manufacturing and engineering of nanocellulose: A review of available data and industrial applications. Journal of Biomaterials and Nanobiotechnology 4: 165188.

6. Flauzino Neto WP, Silvério HA, Dantas NO, Pasquini D (2013) Extraction and characterization of cellulose nanocrystals from agro-industrial residue-soyhulls. Industrial Crops and Products 42: 480-488.

7. Lushnikova AS (2014) Development of technology for label paper based on technical cellulose from rice straw, Ural State Forest Technical University, Yekaterinburg, p. 83.

8. Azizi-Samir MAS, Alloin F, Dufresne A (2005) Review of recent research into cellulosic whiskers, their properties and their application in nanocomposite field. Biomacromolecules 6(2): 612-626. 